\title{
Improved optical properties of InAs quantum dots for intermediate band solar cells by suppression of misfit strain relaxation
}

H. Xie, R. Prioli, A. M. Fischer, F. A. Ponce, R. M. S. Kawabata, L. D. Pinto, R. Jakomin, M. P. Pires, and P. L. Souza

Citation: Journal of Applied Physics 120, 034301 (2016); doi: 10.1063/1.4958871

View online: http://dx.doi.org/10.1063/1.4958871

View Table of Contents: http://aip.scitation.org/toc/jap/120/3

Published by the American Institute of Physics

\section{Articles you may be interested in}

Effect of electric field on carrier escape mechanisms in quantum dot intermediate band solar cells Journal of Applied Physics 121, 013101 (2017); 10.1063/1.4972958

High saturation intensity in InAs/GaAs quantum dot solar cells and impact on the realization of the intermediate band concept at room-temperature

Applied Physics Letters 110, 061107 (2017); 10.1063/1.4975478

Intermediate band solar cells: Recent progress and future directions

Applied Physics Reviews 2, 021302 (2015); 10.1063/1.4916561

Role of charge separation on two-step two photon absorption in InAs/GaAs quantum dot intermediate band solar cells

Applied Physics Letters 108, 063901 (2016); 10.1063/1.4941793

Suppression of thermal carrier escape and efficient photo-carrier generation by two-step photon absorption in InAs quantum dot intermediate-band solar cells using a dot-in-well structure

Journal of Applied Physics 116, 063510 (2014); 10.1063/1.4892826

InAs quantum dot growth on $\mathrm{Al}_{\mathrm{x}} \mathrm{Ga}_{1-\mathrm{x}} \mathrm{As}$ by metalorganic vapor phase epitaxy for intermediate band solar cells Journal of Applied Physics 116, 093511 (2014); 10.1063/1.4894295

\section{AlP | Journal of}

Save your money for your research.

It's now FREE to publish with us no page, color or publication charges apply.

\section{Publish your research in the} Joumal of Applied Physics

to claim your place in applied

physics history. 


\title{
Improved optical properties of InAs quantum dots for intermediate band solar cells by suppression of misfit strain relaxation
}

\author{
H. Xie,,$^{1,2}$ R. Prioli, ${ }^{1,3}$ A. M. Fischer, ${ }^{1}$ F. A. Ponce,,${ }^{1, a)}$ R. M. S. Kawabata, ${ }^{4,5}$ L. D. Pinto, ${ }^{4,5}$ \\ R. Jakomin, ${ }^{5,6}$ M. P. Pires, ${ }^{5,7}$ and P. L. Souza, ${ }^{4,5}$ \\ ${ }^{1}$ Department of Physics, Arizona State University, Tempe, Arizona 85287-1504, USA \\ ${ }^{2}$ School for Engineering of Matter, Transport, and Energy, Arizona State University, Tempe, \\ Arizona 85287-6106, USA \\ ${ }^{3}$ Departamento de Física, Pontificia Universidade Católica do Rio de Janeiro, Marques de São \\ Vicente 225, Rio de Janeiro 22452-900 RJ, Brazil \\ ${ }^{4}$ LabSem, CETUC, Pontificia Universidade Católica do Rio de Janeiro, Marques de São Vicente 225 , \\ Rio de Janeiro 22452-900 RJ, Brazil \\ ${ }^{5}$ Instituto Nacional de Ciência e Tecnologia de Nanodispositivos Semicondutores - DISSE - PUC-Rio, \\ RJ, Brazil \\ ${ }^{6}$ Campus de Xerem, UFRJ, Duque de Caxias-RJ, Brazil \\ ${ }^{7}$ Instituto de Física, UFRJ, Rio de Janeiro-RJ, Brazil
}

(Received 5 April 2016; accepted 4 July 2016; published online 15 July 2016)

\begin{abstract}
The properties of InAs quantum dots (QDs) have been studied for application in intermediate band solar cells. It is found that suppression of plastic relaxation in the QDs has a significant effect on the optoelectronic properties. Partial capping plus annealing is shown to be effective in controlling the height of the QDs and in suppressing plastic relaxation. A force balancing model is used to explain the relationship between plastic relaxation and QD height. A strong luminescence has been observed from strained QDs, indicating the presence of localized states in the desired energy range. No luminescence has been observed from plastically relaxed QDs. Published by AIP Publishing.

[http://dx.doi.org/10.1063/1.4958871]
\end{abstract}

\section{INTRODUCTION}

The realization of electron confinement in nanostructures has triggered the development of novel optoelectronic devices. Quantum dots (QDs), made of a material with lower bandgap than the surrounding semiconductor, create threedimensional potential wells that lead to carrier localization and discrete energy levels. Unlike quantum wells and quantum wires, the electronic states of the QDs are isolated from the conduction and valence bands with a zero density of states in between. ${ }^{1}$ QD-based structures have resulted in the successful development and commercialization of singleelectron transistors, ${ }^{2-4}$ diode lasers, ${ }^{5-8}$ and photodetectors. ${ }^{9}$ Currently, there is much interest in the application of QDs for intermediate band solar cells.

The use of an intermediate band has been proposed for semiconductor solar cells in order to overcome the ShockleyQueisser limit by increasing the photocurrent while preserving the output voltage of the main semiconductor. ${ }^{10}$ This concept may be achieved by introducing states in the bandgap, which in sufficient densities overlap in space creating an intermediate band. Such intermediate band allows two additional transition paths for light absorption, with a theoretical efficiency similar to a triple-junction solar cell connected in series. ${ }^{11}$ The new transition paths are from the valence band to the intermediate band and from the intermediate band to the conduction band, corresponding to two additional sub-bandgaps. A detailed-balance model predicts optimum values of $1.96 \mathrm{eV}$

\footnotetext{
${ }^{\text {a) }}$ Author to whom correspondence should be addressed. Electronic mail: ponce@asu.edu.
}

for the main bandgap, and $1.24 \mathrm{eV}$ and $0.72 \mathrm{eV}$ for the subbandgaps, resulting in a photovoltaic efficiency of about $63 \%$ under maximum solar concentration. ${ }^{12}$

The InAs QD system has been explored for applications in intermediate band solar cells (IBSCs), taking advantage from knowledge derived from other optoelectronic applications. ${ }^{13,14}$ A high density of InAs quantum dots embedded in GaAs is expected to result in an intermediate band due to the overlap of the three-dimensional confined states. ${ }^{15} \mathrm{~A}$ weakness in the InAs/GaAs system is in the experimentally determined bandgaps $(1.2,1.0 \text {, and } 0.2 \mathrm{eV})^{16}$ that differ from the ideal values. $\mathrm{Al}_{\mathrm{x}} \mathrm{Ga}_{1-\mathrm{x}} \mathrm{As}$ alloys have been used as a matrix to approach the optimum bandgap value. ${ }^{15,17} \operatorname{In}_{\mathrm{x}} \mathrm{Ga}_{1-\mathrm{x}} \mathrm{As}$ quantum dots with spherical symmetry, ${ }^{15}$ as well as fully strained lens-shaped InAs QDs, ${ }^{17}$ have been reported to approach the optimum sub-bandgap values. An important aspect of InAs QDs in an (Al)GaAs matrix is the large difference in lattice parameter between the QDs and the matrix. The lattice mismatch is necessary for the formation of a twodimensional wetting layer followed by island (QD) growth, described by the Stranski-Krastanov (SK) growth mode. ${ }^{18}$ However, the lattice mismatch strain can be relaxed by the generation of misfit dislocations, ${ }^{19-21}$ which can degrade the photocurrent in a QD photovoltaic device. ${ }^{15}$ In thin film epitaxy, plastic relaxation takes place after the film thickness reaches a critical value. ${ }^{22}$ The height (thickness) of the QD can be controlled using a thin capping layer to partially cover the QDs, followed by a high temperature anneal. ${ }^{23}$ This process, known in molecular beam epitaxy as indium flushing, removes the top of the dots above the capping level, converting the dots into disks of approximately equal height. The 
use of this approach on InAs QDs grown on GaAs has been reported to result in superior electric and optical properties. ${ }^{24}$ More recently, InAs QDs on AlGaAs using a similar approach, but grown by metalorganic vapor phase epitaxy (MOVPE), have shown improved structure quality and optical response. ${ }^{17}$

In this report, we show that suppression of plastic relaxation has a significant effect on the optoelectronic properties of InAs QD-based thin film structures. We use partial capping plus anneal to control the height of InAs QDs and to suppress plastic relaxation. A force balancing model is used to explain the relationship between plastic relaxation and QD height. Strong luminescence from the strained QDs has been observed, indicating the presence of localized states in the desired energy range. No luminescence has been observed from QDs that exhibit plastic relaxation.

\section{EXPERIMENTAL DETAILS}

The InAs/AlGaAs QD structure was grown by MOVPE in an Aixtron AIX 200 horizontal reactor at 100 mbar on $n$-doped (001) GaAs substrates, with a total hydrogen carrier gas flow of 8 liters/min. Tri-methyl aluminum (TMAl), trimethyl gallium (TMGa), tri-methyl indium (TMIn), and arsine $\left(\mathrm{AsH}_{3}\right)$ precursors were used as $\mathrm{Al}, \mathrm{Ga}$, In, and As sources. $\mathrm{CBr}_{4}$ and $\mathrm{SiH}_{4}$ were used for $p$ - and $n$-type doping. The $\mathrm{Al} / \mathrm{III}$ gas phase was calibrated for the growth of $\mathrm{Al}_{0.3} \mathrm{Ga}$ ${ }_{0.7} \mathrm{As}$ layers, with a growth rate of $1 \mathrm{~nm} / \mathrm{s}$ and a V/III ratio of 14.9. The growth of GaAs layers was at a rate of $0.65 \mathrm{~nm} / \mathrm{s}$, a $\mathrm{V} / \mathrm{III}$ ratio of 23.3 , and a growth temperature of $630^{\circ} \mathrm{C}$. The GaAs substrates were subjected to a de-oxidation pre-growth treatment at $720^{\circ} \mathrm{C}$ for 15 min with an $\mathrm{AsH}_{3}$ overpressure.

The growth sequence is as follows: A 500-nm-thick Si-doped $\left(1 \times 10^{18} \mathrm{~cm}^{-3}\right) n$-GaAs buffer layer is grown at $630^{\circ} \mathrm{C}$ on a GaAs (001) substrate, followed by a $300-\mathrm{nm}$ thick $n$-type Si-doped $\left(5 \times 10^{17} \mathrm{~cm}^{-3}\right)$ and a 100 -nm-thick undoped $\mathrm{Al}_{0.3} \mathrm{Ga}_{0.7} \mathrm{As}$ layers. The temperature is then lowered to $490^{\circ} \mathrm{C}$ with a ramping time of $\sim 4 \mathrm{~min}$, plus $1.5 \mathrm{~min}$ at that temperature for surface stabilization. Next, the first layer of InAs QDs is grown with a V/III ratio of 6.4 , a growth time of $2.4 \mathrm{~s}$, and at an estimated growth rate of $0.7 \mathrm{~nm} / \mathrm{s}$. The dots are $n$-type doped using the same $\mathrm{SiH}_{4}$ flow as was used to dope GaAs. After the QD growth, the temperature is maintained fixed for $12 \mathrm{~s}$, and a GaAs capping layer is grown at a constant temperature of $490^{\circ} \mathrm{C}$. The capping layer thickness was varied from complete coverage with a 20-nmthick layer (sample A) down to partial capping with a 5-nmthick layer (sample B). The temperature is then raised to $630{ }^{\circ} \mathrm{C}$ with a ramping time of $4 \mathrm{~min}$ followed by $1.5 \mathrm{~min}$ settling time for surface stabilization. Afterwards, a $90 \mathrm{~nm}$ $\mathrm{Al}_{0.3} \mathrm{Ga}_{0.7} \mathrm{As}$ barrier is grown. Ten periods of the QDs, capping layer, and $\mathrm{AlGaAs}$ barrier were deposited to produce the active region in the device, shown schematically in Fig. 1. After the active region, the temperature was kept at $630{ }^{\circ} \mathrm{C}$ to grow a 100 -nm-thick $p$-doped $\left(5 \times 10^{17} \mathrm{~cm}^{-3}\right)$ AlGaAs layer, followed by a $200 \mathrm{~nm} p^{+}$-AlGaAs window layer, and a $30 \mathrm{~nm}$ thick $p^{+}$-GaAs $\left(2 \times 10^{18} \mathrm{~cm}^{-3}\right)$ contact layer.

Cross-section samples were prepared for TEM by mechanical wedge polishing followed by argon-ion milling at a

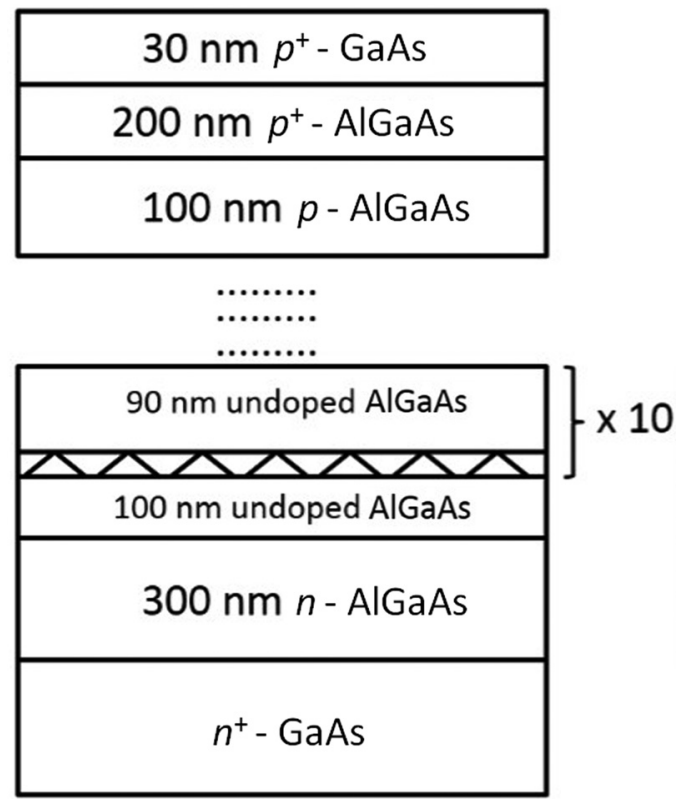

FIG. 1. Schematic diagram of the thin film structure consisting of 10 periods of InAs QDs with GaAs capping layers and $\mathrm{Al}_{0.3} \mathrm{Ga}_{0.7} \mathrm{As}$ barriers.

$2 \mathrm{kV}$ accelerating voltage and liquid $\mathrm{N}_{2}$ temperatures. Twobeam diffraction contrast TEM was performed in a Philips CM 200 instrument to determine the nature of local strain variation. The morphology of the InAs dots was studied by scanning transmission electron microscopy (STEM) using a high-angle annular dark-field (HAADF) detector, ${ }^{25}$ in an aberrationcorrected JEOL ARM 200 scanning transmission electron microscope. Both instruments were operated at $200 \mathrm{kV}$.

Photoluminescence spectra were taken at low temperatures $(\sim 10 \mathrm{~K})$ using a diode-pumped solid-state (DPSS) laser operated at $532 \mathrm{~nm}$. The laser power level was varied between 0.5 and $6.4 \mathrm{~mW}$, with a beam radius of $\sim 0.54 \mathrm{~mm}$. A liquid $\mathrm{N}_{2}$ cooled $\mathrm{Ge}$ detector was used to collect spectra in the wavelength range from 800 to $1600 \mathrm{~nm}$.

\section{RESULTS AND DISCUSSION}

\section{A. Control of the height of InAs dots}

The STEM-HAADF images were produced under axial illumination with transmitted electrons that are scattered into high angles (90-150 mrad). Since the scattering angle depends on the atomic number, brighter contrast is associated with higher atomic numbers. Figure 2 shows images of two layers of QDs for samples A and B. The QDs in sample A (Fig. 2(a)) are lens shaped, and most of them are fully covered by the 20-nm-thick GaAs capping layer, which preserves the QD shape during the annealing step. In the magnified image (Fig. 2(b)), two bright contrast layers are observed below and above the QD. The lower layer corresponds to the indium-rich wetting layer that precedes the formation of the QD in the SK growth mode. The upper layer results from trapping of indium that is segregated during growth of the GaAs capping layer, ${ }^{26}$ and is blocked by the AlGaAs barrier. ${ }^{27}$ For sample B (Fig. 2(c)), the dots have a uniform height resulting from the 5-nm-thick capping layer, with a flat top surface due to the truncation of its top portion by the lateral diffusion induced by 

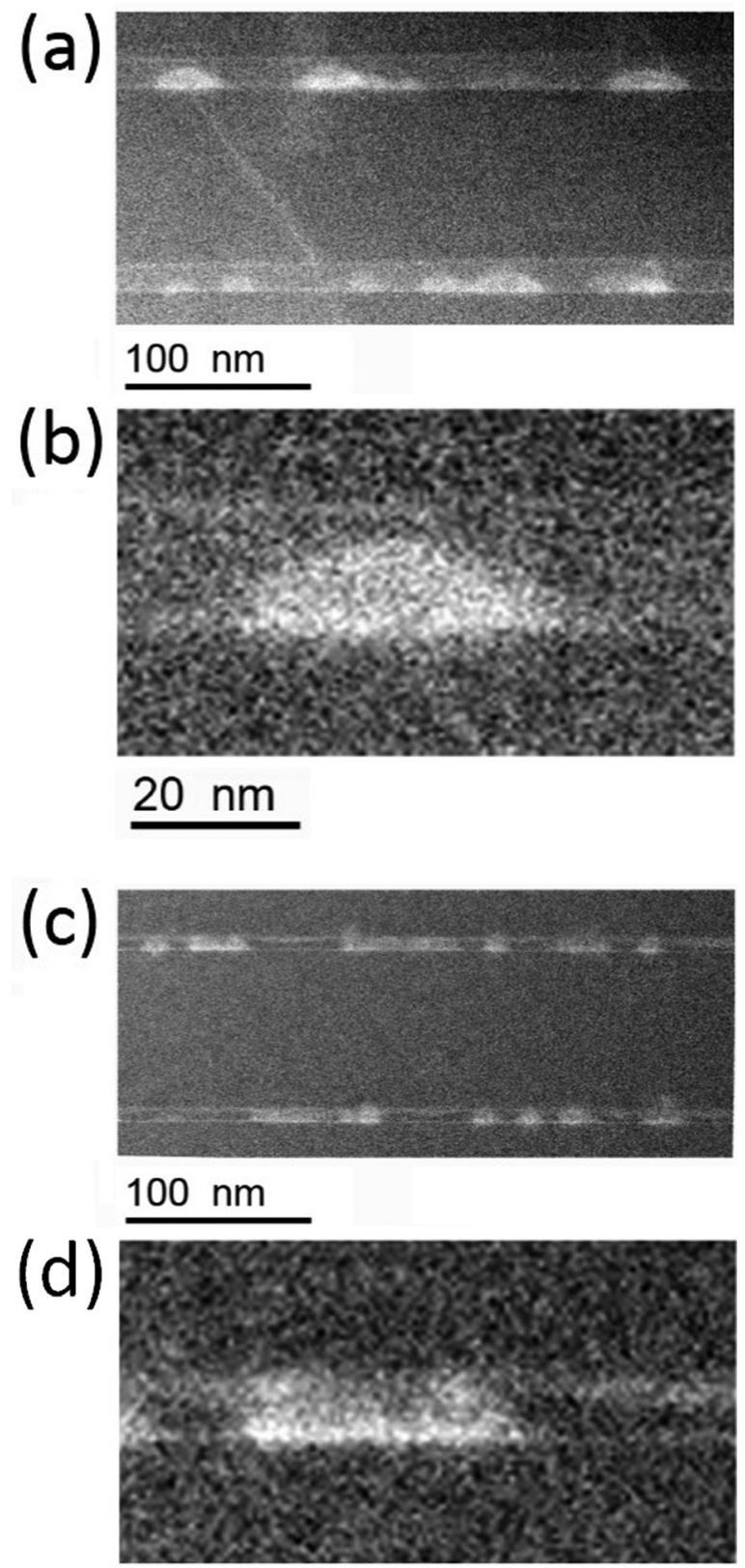

$20 \mathrm{~nm}$

FIG. 2. Cross-section high-angle annular dark-field STEM images of (a) sample A ( $20 \mathrm{~nm}$ capping layer) with (b) a higher magnification image of a single QD; and of (c) sample B (5 nm capping layer) with (d) a higher magnification image of a single QD. Brighter contrast in these images corresponds to higher average atomic numbers.

the thermal annealing step. The magnified image (Fig. 2(d)) shows the SK wetting layer under the QD, and a bright layer on top of the QD (which is thicker than in sample A). We attribute the latter to diffused indium from the top portion of the QD in addition to the trapped indium by the AlGaAs layer described for sample A.

\section{B. Suppression of misfit strain relaxation}

A large difference in the microstructure resulting from the capping-plus-anneal step is observed by TEM. The microstructure of the films was studied by two-beam diffraction-contrast bright-field imaging, which shows contrast associated with bent crystal planes due to strain. Threading dislocations were observed associated with QDs with a capping thickness of 20-nm (sample A) but not for capping thickness of 5-nm (sample B). In Fig. 3(a), sample A is viewed in cross-section along the [110] projection with $\boldsymbol{g}=2 \overline{2} 0$. It shows dislocations emanating from some of the dots, forming a V-shape pattern with branches lying on (111) and (i11) planes. Similar patterns have been reported in the literature. ${ }^{28}$ The dislocations show dark contrast under $\boldsymbol{g}=2 \overline{2} 0$, signifying that the Burgers vectors have an edge component along [110]. Thus, the segments of the dislocations lying on the (001) plane of the InAs/AlGaAs interface have an edge component that relaxes the misfit strain in a given QD. The microstructure of sample B is shown in Fig. 3(b). The two-beam diffraction contrast image shows no evidence of threading dislocations, suggesting coherently strained QDs embedded in the matrix.

At higher magnification, the QDs in sample A (Fig. 4(a)) show moiré fringes perpendicular to the diffraction vector $g$ caused by the overlap along the electron beam projection of the QDs with the surrounding lattice. ${ }^{29}$ The moiré fringes imply strain relaxation in the QDs, with loss of coherence due to the presence of misfit dislocations. The image at higher magnification for sample B (Fig. 4(b)) shows for each QD two lobes of dark contrast with a bright region in the middle (perpendicular to $g$ ). This is known as Ashby-Brown contrast, which is typical for coherent precipitates where

(a)

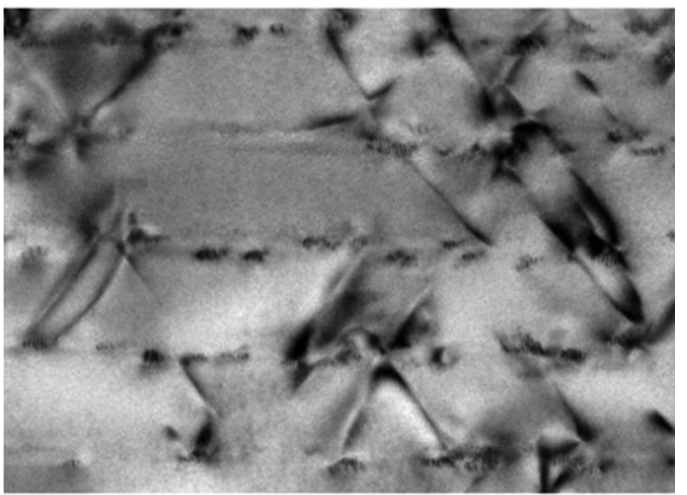

(b)

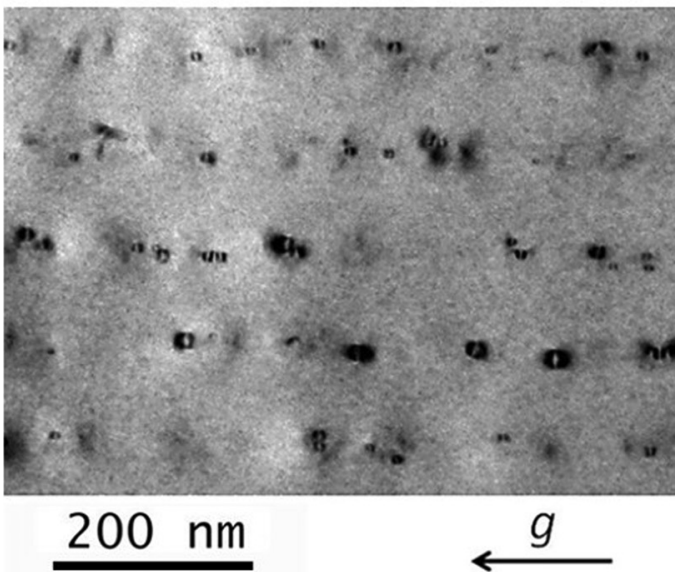

FIG. 3. Two-beam diffraction-contrast bright-field TEM images of the QD region in (a) sample $\mathrm{A}$ and (b) sample $\mathrm{B}$, taken under $\boldsymbol{g}=2 \overline{2} 0$ condition. Threading dislocations are observed in sample A. 
(a)

(b)
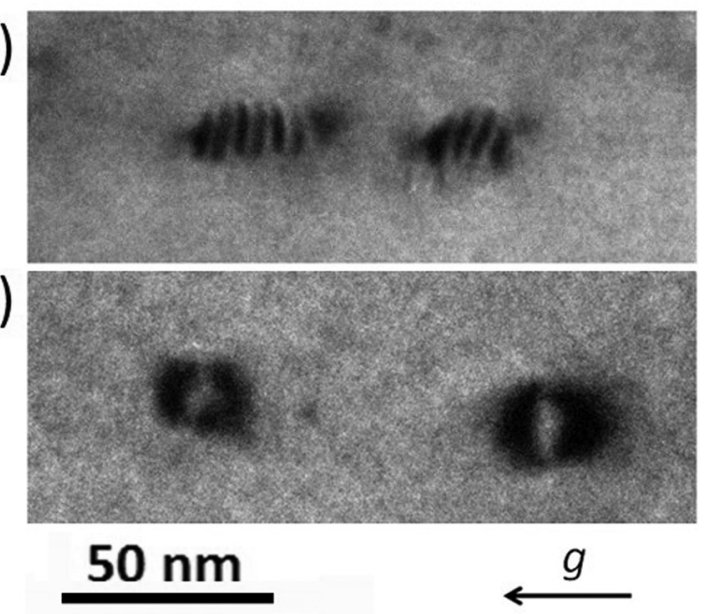

FIG. 4. Two-beam diffraction-contrast bright-field TEM images of QDs in (a) sample A and (b) sample B, under $g=2 \overline{2} 0$ condition. QDs in sample A exhibit moiré fringes. QDs in sample B show Ashby-Brown contrast.

symmetric bending of crystal planes is produced by elastic strain and absence of strain relaxation. ${ }^{30}$

High-resolution HAADF images of two InAs QDs are shown in Fig. 5. The smaller QD (Fig. 5(a)) does not show dislocation loops, indicating a fully strained state as depicted schematically (Fig. 5(b)). On the other hand, a 6-nm-high larger dot (Fig. 5(c)) has misfit dislocation loops characterized by missing planes inside the QDs ending at the QD boundaries. The resulting $60^{\circ}$ dislocations are labeled in the schematic diagram (Fig. 5(d)), some of which join to form Lomer dislocations. In the figure, one dislocation fails to form a loop and threads up towards the top surface.

To understand the misfit strain relaxation in InAs QDs, we consider the forces acting on a misfit dislocation loop surrounding the dot. One force is due to the misfit strain promoting the creation of misfit dislocation loops and another is the dislocation loop line tension aiming to minimize the total length of the dislocations. We approximate the problem by considering the InAs QD as a disk with two surfaces parallel to the growth plane, with the disk height determined by the capping layer thickness and the disk diameter much larger than its height. Parallel segments of the dislocation loops surrounding the disks form dipoles (i.e., dislocations with equal but opposite Burgers vectors). The segments lying on the top and bottom interfaces exert an attractive force on each other. ${ }^{31}$ We use the model developed by Fischer et al. ${ }^{32}$ to calculate the critical separation (QD height) at which the two forces are equal in magnitude. The model deals with the relaxation of strained layers using an equilibrium approach that includes the elastic interaction of dislocation dipoles. In the original model, the dipole consists of a real dislocation at a heterointerface plus an image dislocation across a free surface. This method has been used to correctly predict the critical thickness for strained GeSi films on silicon. ${ }^{32}$ We use the same approach to determine the critical thickness for a double heterointerface associated with a buried InAs disk.

For simplicity, we assume in our calculations that the dislocations in a dipole are aligned in the vertical direction.
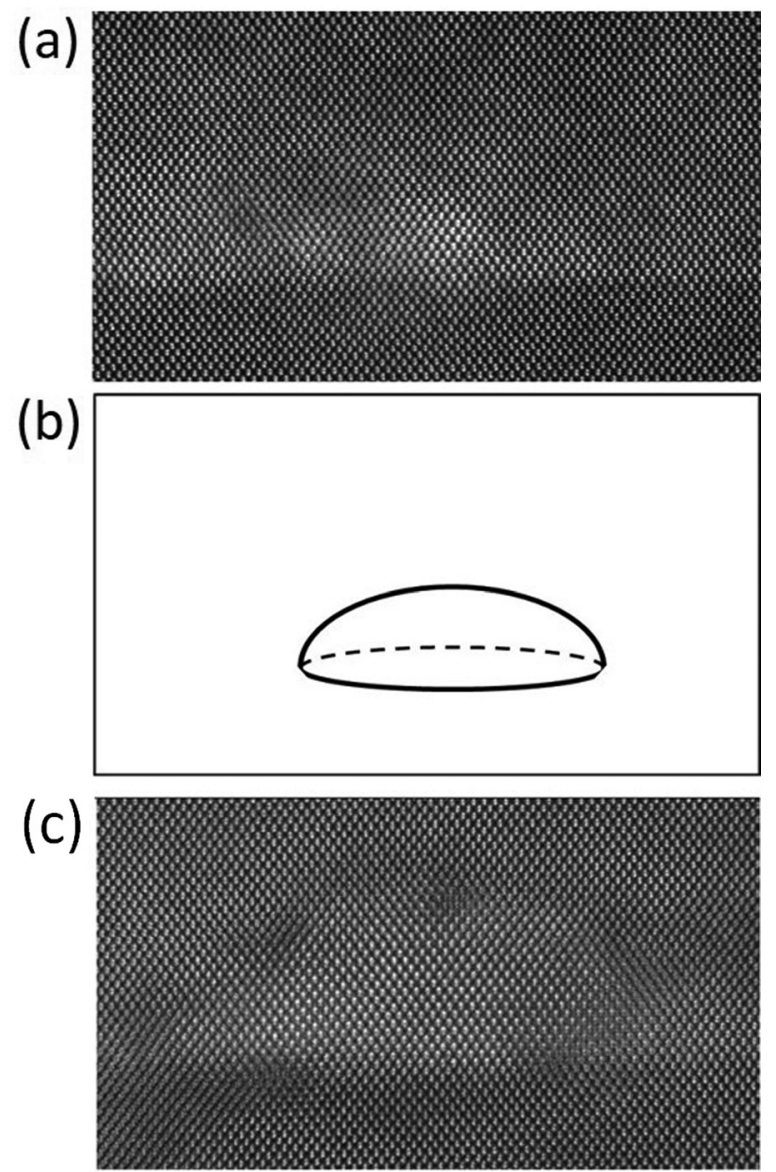

(d)

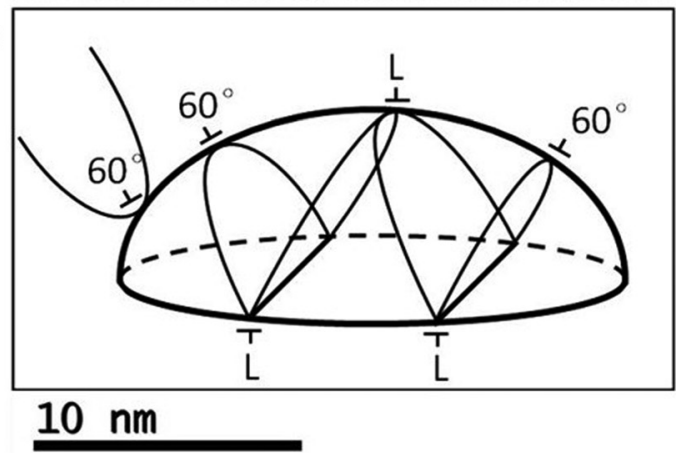

FIG. 5. High-resolution HAADF images show the atomic arrangement of (a) $3 \mathrm{~nm}$ and (c) $6 \mathrm{~nm}$ thick InAs dots, viewed in the [110] projection. Schematic diagrams in (b) show the absence of dislocations, and in (d) the location of dislocation loops around the QDs. $60^{\circ}$ dislocations tend to combine into Lomer dislocations (L). A dislocation loop (left) fails to wrap around the InAs dot and threads towards the surface.

This is an approximation since the dislocations in a dipole lie on a $\{111\}$ slip plane (Fig. 5(d)). Figure 6(a) shows the alignment of $60^{\circ}$ dislocation pairs separated by a distance $h$, forming dislocation dipoles. For the lateral interaction, we have also simplified by considering dislocations loops with the same Burgers vector. The critical separation below which the dislocation dipole loop collapses, $h_{c}$, is calculated as a function of lattice mismatch using the excess shear stress given by the following equation: ${ }^{32}$

$$
\begin{aligned}
\tau_{\text {exc }}= & \cos \lambda \cos \phi[2 G(1+\nu) /(1-\nu)] \\
& \times\left\{\varepsilon-\left[b \cos \lambda /\left(2 R_{h, p}\right)\right](1+\beta)\right\}=0,
\end{aligned}
$$


(a)

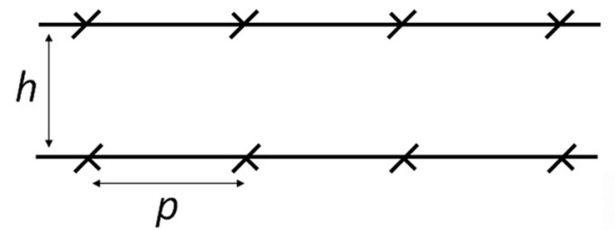

(b)

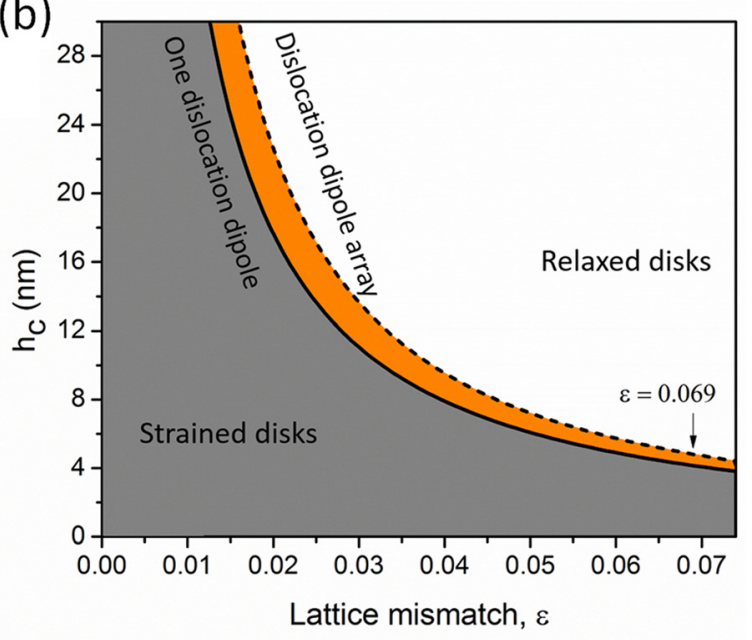

FIG. 6. (a) Schematic diagram of the simplified model used to determine the critical thickness. (b) Equilibrium force calculation of the critical thickness as a function of lattice mismatch, for a single dislocation dipole and for a periodic array of dislocation dipoles.

$$
\begin{gathered}
\beta=\left\{[1-(\nu / 4)] /\left[4 \pi \cos ^{2} \lambda(1+\nu)\right]\right\} \ln \left(R_{h, p} / b\right), \\
R_{h, p}=\left(\frac{4}{h^{2}}+\frac{4}{p^{2}}\right)^{-1 / 2},
\end{gathered}
$$

where $\lambda=60^{\circ}$ is the angle between the Burgers vector and the direction in the interface plane that is normal to the dislocation line, $\phi=35.3^{\circ}$ is the angle between the slip plane and the strained interface normal, $G$ is the shear modulus, $\nu=0.35$ is the Poisson ratio, ${ }^{33} \varepsilon=2\left(a_{1}-a_{2}\right) /\left(a_{1}+a_{2}\right)$ is the lattice mismatch, $b$ is the magnitude of the Burgers vector, and $h$ is the separation between the two segments of the dislocation dipole. $p$ is the lateral separation between two dislocations, which is a function of the lattice parameters of the two materials, $\left(p=a_{1} a_{2} /\left(a_{1}-a_{2}\right)\right)$. The magnitude of the Burgers vector of a $60^{\circ}$ dislocation in InAs is $b=a / \sqrt{2}$ $=0.428 \mathrm{~nm} \cdot{ }^{34}$ Note that $h$ in the equation represents the distance between dislocations in the dipole, while in the original Fischer's equation it represents half that value.

In Fig. 6(b), the solid and dashed curves show $h_{c}$ for one dislocation dipole $(p \rightarrow+\infty)$ and for an array of dislocation dipoles corresponding to full strain relaxation. Using the lattice parameters for InAs $(0.6058 \mathrm{~nm})$ and GaAs $(0.5654 \mathrm{~nm}),{ }^{34}$ we obtain values of the lattice mismatch $\varepsilon=0.069$. and $p=8.5 \mathrm{~nm}$. Thus, the model predicts a critical thickness of $4 \mathrm{~nm}$ for InAs/ AlGaAs QDs. This is in agreement with TEM observations that show the transition from strained to relaxed QDs occurs at a height of about $6 \mathrm{~nm}$. This explains the suppression of strain relaxation in QDs whose height is limited to $5 \mathrm{~nm}$, below the critical thickness. We expect that the approximations mentioned above will cause only a small difference in the resulting critical thickness value. In fact, the difference between a single loop and an array of loops is relatively small for a lattice mismatch $\varepsilon=0.069$ (Fig. 6(b)).

\section{Effect on the optical properties of the suppression of misfit strain relaxation}

Plastic relaxation is observed to have a negative effect on the optical properties of the InAs QDs. This has been observed in the photoluminescence spectra of our samples, taken at $10 \mathrm{~K}$ and shown in Fig. 7(a). The emission peak at $1.49 \mathrm{eV}$ corresponds to the GaAs capping layer; for which the intensity of sample A is $\sim 0.4$ times the intensity of sample B. We attribute the lower intensity to the presence of the dislocations induced by plastic relaxation. A weak emission is observed centered at $\sim 1.46 \mathrm{eV}$ in both samples, which we attribute to the InAs wetting layer. Another weak emission is observed in sample A at $1.43 \mathrm{eV}$; which we attribute to the In-rich layer that is present on top of the GaAs capping layer, and appears as bright lines in Fig. 2(b). In sample B, the top of the InAs dots is spread over the capping layer by the annealing step, forming the In-rich layer on top of the GaAs capping layer in Fig. 2(d). This layer is thicker than in sample $\mathrm{A}$ and emits with a peak at $1.39 \mathrm{eV}$. A strong emission is observed in the $1.21-1.35 \mathrm{eV}$ range for sample B, which lacks dislocations, and present uniform dot height caused by the annealing step. No such emission is observed in sample A,

(a)
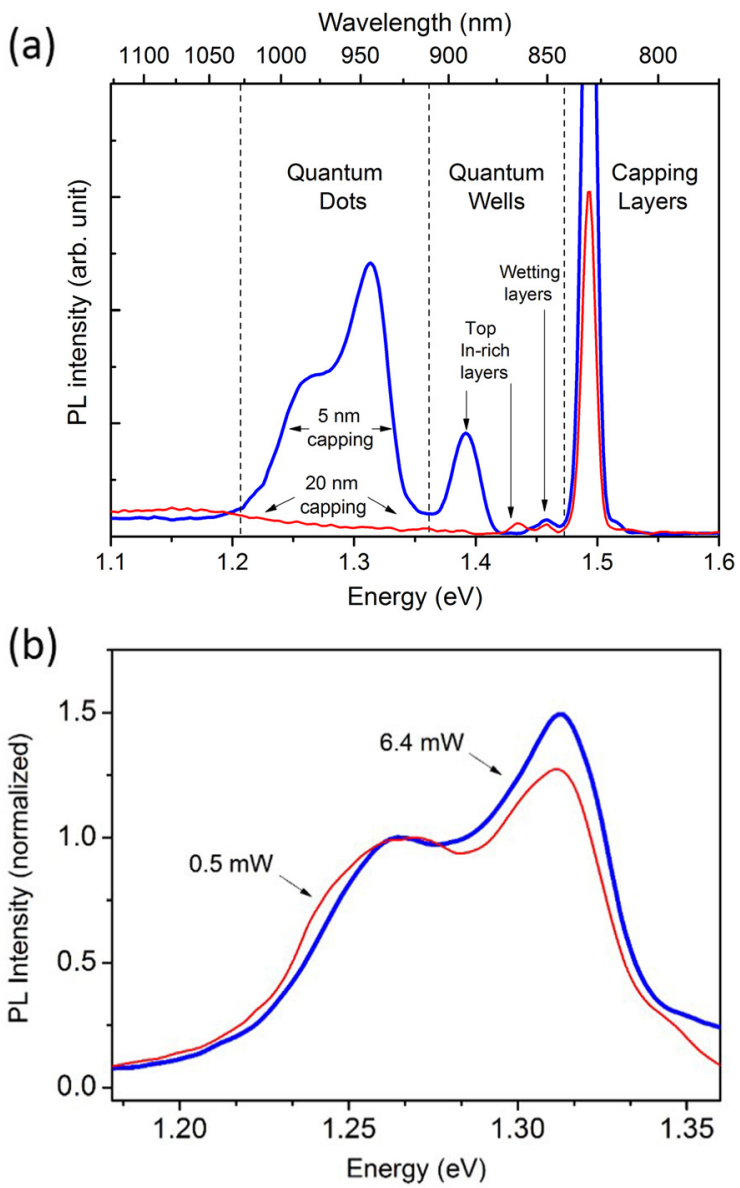

FIG. 7. (a) Photoluminescence spectra for relaxed QDs (sample A) and for strained QDs (sample B). (b) QD photoluminescence spectra of sample B for excitation power densities of 0.5 and $6.4 \mathrm{~mW}$. 
which we attribute to dislocation acting as non-radiative recombination centers. The emission in sample B can be assigned to ground-state and excited-state transitions in the QDs. ${ }^{35}$ The dependence of this emission on excitation power is shown in Fig. 7(b). The spectra have been normalized, taking the peak at $1.26 \mathrm{eV}$ as a reference. The relative intensity of the excited peak increases with excitation power, as expected. The inter-sublevel energy spacing between the two peaks $(\sim 50 \mathrm{meV})$ is in good agreement with reported experiments and calculations. ${ }^{36-38}$ Indeed, the PL data, where sample B exhibits better optical properties with a stronger emission corresponding to the QDs transitions, show that high-efficiency QD nanostructure with the desired energy level characteristics for intermediate band solar cells can be achieved by suppression of the misfit-strain relaxation in InAs QDs.

\section{CONCLUSIONS}

We have shown that the transition from relaxed to strained QDs grown by MOVPE can be controlled by partial capping followed by annealing at higher temperatures. We have successfully suppressed plastic strain relaxation in InAs dots by depositing a 5-nm-thick capping layer followed by annealing, which sets the height of the InAs dots below the critical value for dislocation generation. The suppression of plastic strain relaxation in the InAs dots is confirmed by the presence of moiré fringes for the relaxed dots and AshbyBrown contrast for the strained dots. The experimental observations and the calculation of the critical height are in good agreement, indicating the interplay between strain and dislocation line tension. We have found direct evidence that optical transitions in InAs/ $\mathrm{Al}_{0.3} \mathrm{Ga}_{0.7} \mathrm{As}$ QDs are strongly affected by the presence of defects associated with plastic relaxation. The suppression of plastic strain relaxation by control of the QD height generates effective gap states for applications to optoelectronic devices. This is particularly useful for intermediate band solar cells, in order to overcome the standard solar cell efficiency limit and to achieve improved harvesting of light for energy conversion.

\section{ACKNOWLEDGMENTS}

The research at ASU was supported in part by the National Science Foundation (NSF) and the Department of Energy (DOE) under NSF CA No. EEC-1041895, and in part by the NSF Materials World Network (DMR-1108450). The material design and growth was partially supported by the Fundação de Amparo a Pesquisa do Estado de Rio de Janeiro (FAPERJ) and by the Conselho Nacional de Desenvolvimento Científico e Tecnológico (CNPq).

${ }^{1}$ A. Luque, A. Marti, N. Lopez, E. Antolin, E. Canovas, C. Stanley, C. Farmer, L. J. Caballero, L. Cuadra, and J. L. Balenzategui, Appl. Phys. Lett. 87, 083505 (2005).
${ }^{2}$ M. A. Kastner, Rev. Mod. Phys. 64, 849 (1992).

${ }^{3}$ S. Ihara, A. Andreev, D. A. Williams, T. Kodera, and S. Oda, Appl. Phys. Lett. 107, 013102 (2015).

${ }^{4}$ S. J. MacLeod, A. M. See, A. R. Hamilton, I. Farrer, D. A. Ritchie, J. Ritzmann, A. Ludwig, and A. D. Wieck, Appl. Phys. Lett. 106, 012105 (2015).

${ }^{5}$ Y. Arakawa and H. Sakaki, Appl. Phys. Lett. 40, 939 (1982).

${ }^{6}$ Y. Narukawa, Y. Kawakami, M. Funato, S. Fujita, S. Fujita, and S. Nakamura, Appl. Phys. Lett. 70, 981 (1997).

${ }^{7}$ D. Bimberg, N. Kirstaedter, N. N. Ledentsov, Z. I. Alferov, P. S. Kopev, and V. M. Ustinov, IEEE J. Sel. Top. Quantum Electron. 3, 196 (1997).

${ }^{8}$ D. L. Huffaker, G. Park, Z. Zou, O. B. Shchekin, and D. G. Deppe, Appl. Phys. Lett. 73, 2564 (1998).

${ }^{9}$ S. Maimon, E. Finkman, G. Bahir, S. E. Schacham, J. M. Garcia, and P. M. Petroff, Appl. Phys. Lett. 73, 2003 (1998).

${ }^{10}$ A. Luque and A. Martí, Phys. Rev. Lett. 78, 5014 (1997).

${ }^{11}$ A. Luque, A. Marti, and C. Stanley, Nat. Photonics 6, 146 (2012).

${ }^{12}$ S. P. Bremner, R. Corkish, and C. B. Honsberg, IEEE Trans. Electron Devices 46, 1932 (1999).

${ }^{13}$ D. Bimberg, M. Grundmann, and N. N. Ledentsov, Quantum Dot Heterostructures (John Wiley \& Sons, Chicester, 1999).

${ }^{14}$ K. A. Sablon, J. W. Little, V. Mitin, A. Sergeev, N. Vagidov, and K. Reinhardt, NANO Lett. 11, 2311 (2011).

${ }^{15}$ A. Luque and A. Martí, Adv. Mater. 22, 160 (2010).

${ }^{16}$ E. Antolin, A. Marti, C. D. Farmer, P. G. Linares, E. Hernandez, A. M. Sanchez, T. Ben, S. I. Molina, C. R. Stanley, and A. Luque, J. Appl. Phys. 108, 064513 (2010).

${ }^{17}$ R. Jakomin, R. M. S. Kawabata, R. T. Mourão, D. N. Micha, M. P. Pires, H. Xie, A. M. Fischer, F. A. Ponce, and P. L. Souza, J. Appl. Phys. 116, 093511 (2014).

${ }^{18}$ D. Leonard, K. Pond, and P. Petroff, Phys. Rev. B 50, 11687 (1994).

${ }^{19}$ K. Tillmann, D. Gerthsen, P. Pfundstein, A. Förster, and K. Urban, J. Appl. Phys. 78, 3824 (1995).

${ }^{20}$ Y. Chen, X. W. Lin, Z. Liliental-Weber, J. Washburn, J. F. Klem, and J. Y. Tsao, Appl. Phys. Lett. 68, 111 (1996).

${ }^{21}$ F. Tinjod and H. Mariette, Phys. Status Solidi B 241, 550 (2004).

${ }^{22}$ J. W. Matthews and A. E. Blakeslee, J. Cryst. Growth 27, 118 (1974).

${ }^{23}$ Z. R. Wasilewski, S. Fafard, and J. P. McCaffrey, J. Cryst. Growth 201, 1131 (1999).

${ }^{24}$ V. Polojarvi, A. Schramm, A. Aho, A. Tukiainen, and M. Guina, J. Phys. D-Appl. Phys. 45, 365107 (2012).

${ }^{25}$ J. Liu and J. M. Cowley, Ultramicroscopy 37, 50 (1991).

${ }^{26}$ H. Toyoshima, T. Niwa, J. Yamazaki, and A. Okamoto, Appl. Phys. Lett. 63, 821 (1993).

${ }^{27}$ A. A. Marmalyuk, O. I. Govorkov, A. V. Petrovsky, D. B. Nikitin, A. A. Padalitsa, P. V. Bulaev, I. V. Budkin, and I. D. Zalevsky, Nanotechnology 12, 434 (2001).

${ }^{28}$ L. Nasi, C. Bocchi, F. Germini, M. Prezioso, E. Gombia, R. Mosca, P. Frigeri, G. Trevisi, L. Seravalli, and S. Franchi, J. Mater. Sci. Electron. 19, S96 (2008).

${ }^{29}$ R. Vincent, Philos. Mag. 19, 1127 (1969).

${ }^{30}$ M. F. Ashby and L. M. Brown, Philos. Mag. 8, 1083 (1963).

${ }^{31}$ J. P. Hirth and J. Lothe, Theory of Dislocations, 2nd ed. (Krieger Publishing Company, Malabar, Florida, 1982), p. 117.

${ }^{32}$ A. Fischer, H. Kuhne, and H. Richter, Phys. Rev. Lett. 73, 2712 (1994).

${ }^{33}$ S. W. Ellaway and D. A. Faux, J. Appl. Phys. 92, 3027 (2002).

${ }^{34}$ O. Madelung, Semiconductors: Data Handbook (Springer, Berlin, Heidelberg, 2004).

${ }^{35}$ M. Grundmann, N. N. Ledentsov, O. Stier, D. Bimberg, V. M. Ustinov, P. S. Kopev, and Z. I. Alferov, Appl. Phys. Lett. 68, 979 (1996).

${ }^{36}$ S. Fafard, Z. R. Wasilewski, C. N. Allen, D. Picard, M. Spanner, J. P. McCaffrey, and P. G. Piva, Phys. Rev. B 59, 15368 (1999).

${ }^{37}$ M. Grundmann, O. Stier, and D. Bimberg, Phys. Rev. B 52, 11969 (1995).

${ }^{38}$ M. Shahzadeh and M. Sabaeian, J. Opt. Soc. Am. B-Opt. Phys. 32, 1097 (2015). 